\title{
Experiência em cuidados paliativos à criança portadora de leucemia: a visão dos profissionais
}

\author{
Experience in palliative care for children with leukemia: \\ the professionals' viewpoint
}

\author{
Danielle Moreira Nascimento ${ }^{1}$ \\ Thaisa Gino Rodrigues ${ }^{1}$ \\ Mayara Rosário Soares ${ }^{1}$ \\ Marina Lira Santos Rosa ${ }^{1}$ \\ Selma Maria da Fonseca Viegas ${ }^{2}$ \\ Patrícia de Oliveira Salgado ${ }^{3}$
}

\footnotetext{
${ }^{1}$ Pontifícia Universidade Católica de Minas Gerais R. Itabira 126, Bela Vista. 35.790-000 Curvelo MG dani.dmn@hotmail.com ${ }^{2}$ Universidade Federal de São João del-Rei.

${ }^{3}$ Universidade Federal de Viçosa.
}

\begin{abstract}
Palliative care is developed through multi-professional assistance with actions to provide support and comfort for the children and their families. The support involves the alleviation of suffering by controlling the pain and its symptoms, as well as ensuring psychosocial and spiritual support. This is a qualitative case study which sought to understand the multidisciplinary view of the team vis-à-vis a child with leukemia in palliative care, in a hospital in Belo Horizonte. The subjects of research were 17 health professionals of the direct assistance team to the child receiving such care and the data were analyzed using the content analysis technique. The professional experience in palliative care is intrinsic to the success and continuity of the patient's care. It was found that the professionals have little experience in this area and have difficulty dealing with their emotions, and sometimes become unable to act when faced with the anguish of those involved and with death. However, despite the fact that the area of activity causes suffering and anguish to the professional, the multi-professional team still identifies with and likes the area, which is important for the children and their families to feel safe, respected and well cared for by the professionals. Key words Palliative care, Child health, Health personnel
\end{abstract}

Resumo O cuidado paliativo desenvolve-se por meio de assistência multiprofissional com ações de suporte e conforto para a criança e sua família. O suporte se constitui do alívio do sofrimento pelo controle da dor e dos sintomas, bem como pelo apoio psicossocial e espiritual. Trata-se de um estudo de caso qualitativo que objetivou compreender a visão da equipe multidisciplinar perante a criança portadora de leucemia em cuidado paliativo, em uma instituição hospitalar de Belo Horizonte. Os sujeitos da pesquisa foram 17 profissionais de saúde da equipe de assistência direta à criança nesses cuidados. Os dados foram submetidos à técnica de análise de conteúdo. A experiência profissional em cuidado paliativo é intrínseca ao sucesso e à continuidade do tratamento do paciente. Verificou-se que os profissionais possuem pouca experiência nessa área e têm dificuldade em lidar com os sentimentos, se sentindo, às vezes, impossibilitados de agir mediante as angústias dos envolvidos e com a morte. Contudo, apesar de a área de atuação gerar sofrimento e angústia ao profissional, percebe-se que a equipe multiprofissional identifica-se e gosta da área o que é importante para a criança e sua família se sentirem seguros, respeitados e acolhidos pelos profissionais. Palavras-chave Cuidados paliativos, Saúde da criança, Pessoal de Saúde 


\section{Introdução}

Quando as possibilidades de cura de uma criança em situação de terminalidade se esgotam, é iniciado o cuidado paliativo. Atualmente se fazem muitos esforços para mudar a cultura dos cuidados ao paciente terminal, entendendo-a como o respeito à existência de diferentes visões do portador de neoplasia, familiar e profissional e ao modo holístico de cuidar ${ }^{1}$. Há potencial para aumentar a proporção de crianças e jovens com câncer que são encaminhados aos serviços de assistência paliativa especializada ${ }^{2}$.

O cuidado paliativo é uma abordagem que promove a qualidade de vida de pacientes e de suas famílias diante de doenças graves e que ameaçam a vida, objetivando a prevenção e o alívio do sofrimento pela dor ou de outros problemas físicos, psicossociais e espirituais. A abordagem paliativa busca manter a dignidade do paciente no final da vida e dar suporte à família na doença e no luto ${ }^{3}$.

A realização de todas as atividades que a intenção paliativa engloba exige trabalho em equipe e busca melhorar a qualidade de vida do paciente terminal. A expressão "cuidados paliativos" indica uma equipe multiprofissional composta por médicos, enfermeiros, técnicos de enfermagem, psicólogos, entre outros, que atuam de forma articulada focando a qualidade de vida do paciente e de sua família ${ }^{4}$.

O profissional de saúde envolvido no processo do cuidado paliativo é visto como ponto de apoio no enfrentamento da doença pela família e pelo doente. Dessa forma, a equipe de saúde tem papel fundamental nos cuidados a serem realizados como na aceitação do diagnóstico, auxílio no convívio com a enfermidade. Esse profissional deve desenvolver a assistência integral estabelecendo a escuta atenta e a comunicação efetiva, objetivando diminuir a ansiedade e o medo da família e da criança, frente ao prognóstico futuro ${ }^{5}$.

A experiência profissional em abordagem paliativa é intrínseca ao sucesso e à continuidade do tratamento da pessoa.

O paciente é quem vivencia o processo do cuidado paliativo e, portanto, necessita de profissionais que estejam junto a ele e a sua família e que possuam experiência para ajudá-lo a enfrentar esse momento ${ }^{1}$.

O cuidar fundamenta-se na troca de sentimentos e experiências que necessita ter, por parte dos envolvidos, confiança, empatia e respeito ${ }^{6}$. $\mathrm{O}$ cuidado ao paciente terminal é realizado por profissionais que se complementam para atender as necessidades dos usuários ${ }^{7}$.

O profissional de saúde tem dificuldade em lidar com a morte, pois, desde a graduação, o conhecimento teórico/prático se fundamenta em prevenção, diagnóstico, tratamento e cura de doenças. Apesar de sempre ser um desafio para os profissionais de saúde, a morte faz parte de seu cotidiano ${ }^{8}$.

$\mathrm{Na}$ literatura, há vários estudos voltados para a preparação da família, afirmando a necessidade e a importância da equipe multidisciplinar nesse contexto. Observando-se, assim, a necessidade de estudos direcionados à visão dos profissionais da saúde perante a experiência que possuem para a realização da assistência paliativa, questiona-se: "Qual a visão da equipe multidisciplinar perante crianças portadoras de leucemia em cuidado paliativo de uma instituição hospitalar de Belo Horizonte - Minas Gerais?"

O estudo objetivou compreender a visão da equipe multidisciplinar perante a criança portadora de leucemia em cuidado paliativo. Este artigo aborda a categoria relacionada ao cotidiano das práticas dos profissionais, sendo a experiência em cuidado paliativo à criança portadora de leucemia, a semântica dos resultados.

\section{Metodologia}

Trata-se de estudo de caso de abordagem qualitativa, adequada para compreender a visão da equipe multidisciplinar perante a criança portadora de leucemia em cuidado paliativo.

Como objeto de investigação, a pesquisa qualitativa dota de:

percurso analítico e sistemático, portanto, tem o sentido de tornar possivel a objetivação de um tipo de conhecimento que tem como matéria-prima opiniões, crenças, valores, representações, relações e ações humanas e sociais sob a perspectiva dos atores em intersubjetividade?

A análise qualitativa apresenta certas características peculiares. É válida, sobretudo, na elaboração das deduções específicas sobre um conhecimento ou uma variável de inferência precisa, e não em inferências gerais ${ }^{10-11}$.

O estudo de caso é uma investigação empírica que procura compreender, em profundidade, um fenômeno contemporâneo, principalmente quando os assuntos tratados sobre este não são claros e evidentes ${ }^{12}$.

O cenário do estudo foi uma instituição hospitalar de Minas Gerais (MG) de grande porte e 
foi escolhida por ser referência em oncologia. Trata-se de uma instituição filantrópica, sem fins lucrativos que possui um diferencial para a saúde dos mineiros em diversas áreas da assistência à saúde.

Os sujeitos da pesquisa foram os profissionais que aceitaram participar voluntariamente do estudo; dentre eles, enfermeiros, técnicos de enfermagem, auxiliares de enfermagem, psicólogo, fisioterapeuta que atenderam aos seguintes critérios de inclusão: prestar assistência direta às crianças portadoras de leucemia em processo de cuidado paliativo; trabalhar na instituição, cenário do estudo. Como critérios de exclusão, adotamos o respeito à decisão do participante, se manifestar desejo de não participar do estudo em qualquer momento de seu desenvolvimento e também ao término do estudo. O estudo não teve como sujeito de pesquisa profissionais médicos devido à falta de oportunidade de entrevistar o único do setor oncológico pediátrico, apesar das indicações dos demais profissionais participantes e de outros colegas desse setor.

O estudo teve como evidência, para a produção dos dados, a entrevista individual fundamentada em um roteiro básico com questões abertas. O sigilo da identidade dos entrevistados foi respeitado pela adoção de pseudônimos por eles escolhidos.

A entrevista foi gravada com permissão prévia, o número de informantes não foi determinado anteriormente, sendo respeitada a saturação dos dados, critério estabelecido em pesquisas qualitativas, isto é, quando as informações tornaram reincidentes sem menosprezar dados poucos incidentes que também foram importantes para a compreensão do tema em estudo ${ }^{13}$.

$A$ análise dos dados obedeceu às fases da Análise de Conteúdo proposta por Bardin ${ }^{10}$. Assim, foi realizada a transcrição das entrevistas na íntegra, leitura flutuante e globalizada das mesmas. Efetuou-se a codificação por meio da agregação e da enumeração dos dados, permitindo atingir uma representação do conteúdo ou de sua expressão. Em seguida à codificação, foi realizada a categorização por critério semântico. Os resultados foram organizados em duas categorias temáticas: 1. Sentimentos, acolhimento e humanização em cuidados paliativos; 2. Experiência em cuidado paliativo à criança portadora de leucemia. Este artigo discute a segunda categoria.

A coleta de dados iniciou-se após a aprovação do projeto pelo Comitê de Ética em Pesquisa da PUC Minas, e no Comitê de Ética da Instituição Hospitalar - cenário do estudo. A pesquisa foi desenvolvida segundo as diretrizes e normas regulamentadoras de pesquisa envolvendo seres humanos, conforme a Resolução CNS 196/96. Esta possui referências da bioética: autonomia, beneficência, não maleficência e justiça sempre com o olhar sobre o individual e o coletivo, assegurando os deveres e direitos da população científica, aos sujeitos da pesquisa e ao Estado ${ }^{14}$.

\section{Resultados e discussão}

\section{Experiência em cuidado paliativo à criança portadora de leucemia}

Os indivíduos entrevistados integram parte da equipe de saúde multiprofissional que tem contato direto com a criança em tratamento paliativo. Os dados obtidos nas entrevistas dos profissionais originaram o quadro a seguir.

No Quadro 1, são identificadas as categorias dos profissionais entrevistados, o número de profissionais de cada categoria, o tempo de atuação em pediatria e o motivo que os levou a escolher o setor como local de trabalho.

A amostra foi constituída por 17 profissionais de saúde que foram representados por: quatro enfermeiros, nove técnicos de enfermagem, dois auxiliares de enfermagem, um psicólogo e um fisioterapeuta. A idade dos profissionais variou entre 25 a 49 anos.

A experiência profissional foi verificada de acordo com o tempo, em anos, de atuação em pediatria. O psicólogo é o profissional com maior tempo de atuação em pediatria, 23 anos. Verifica-se que os enfermeiros apresentam tempo de atuação entre um ano e quatro meses a seis anos; entre os técnicos de enfermagem, seis possuem menos de nove anos de atuação e apenas três possuem mais de nove anos, sendo um período de um ano e quadro meses a 18 anos; os auxiliares de enfermagem possuem de cinco a 13 anos de atuação, e o fisioterapeuta possui dois anos de atuação em pediatria.

Diante dos dados expostos, percebe-se que do total de 17 entrevistados, apenas cinco possuem mais de 10 anos de atuação em pediatria, o que representa 29,41\% dos entrevistados (Quadro 1).

Os dados apresentados mostram que os profissionais possuem pouco tempo de experiência profissional, considerando principalmente que a experiência relatada é na pediatria e não em cuidado paliativo à criança, conforme constatado nos seguintes depoimentos: 
Quadro 1. Número de profissionais entrevistados, tempo de atuação e motivo do ingresso na área pediátrica. Belo Horizonte, 2012.

\begin{tabular}{|c|c|c|c|}
\hline $\begin{array}{c}\text { Categoria } \\
\text { Profissional }\end{array}$ & $\begin{array}{l}\text { Número de } \\
\text { profissionais }\end{array}$ & $\begin{array}{l}\text { Tempo de atuação } \\
\text { na área pediátrica }\end{array}$ & Porque trabalha com a pediatria \\
\hline Enfermeiro & $\begin{array}{l}4 \\
9\end{array}$ & $\begin{array}{l}\text { E1 }-1 \text { ano e } 4 \text { meses } \\
\text { E2 }-3 \text { anos } \\
\text { E3 }-6 \text { anos } \\
\text { E4 }-4 \text { anos }\end{array}$ & $\begin{array}{l}\text { E1 - Identificação } \\
\text { E2 - Sempre trabalhou } \\
\text { E3 - Sempre trabalhou / Identificação } \\
\text { E4 - Apaixonou-se / Gostar }\end{array}$ \\
\hline $\begin{array}{l}\text { Técnico de } \\
\text { Enfermagem }\end{array}$ & $\begin{array}{l}1 \\
1\end{array}$ & $\begin{array}{l}\text { T1 }-5 \text { anos } \\
\text { T2 }-18 \text { anos } \\
\text { T3 }-1 \text { ano e } 4 \text { meses } \\
\text { T4 }-6 \text { anos } \\
\text { T5 }-11 \text { anos } \\
\text { T6 }-14 \text { anos } \\
\text { T7 }-7 \text { anos } \\
\text { T8 }-3 \text { anos } \\
\text { T9 }-7 \text { anos }\end{array}$ & $\begin{array}{l}\text { T1 - Insistência / Gostar } \\
\text { T2- Gostar / Identificou-se } \\
\text { T3 - Gostar/ tem que ter dom } \\
\text { T4 - Setor de maior adaptação } \\
\text { T5 - Caiu de paraquedas / Identificou-se } \\
\text { T6 - Gostar } \\
\text { T7 - Identificação com a área } \\
\text { T8 - Sem preferência / Identificação } \\
\text { T9 - Adquirir experiência / Identificação }\end{array}$ \\
\hline $\begin{array}{l}\text { Auxiliar de } \\
\text { Enfermagem }\end{array}$ & & $\begin{array}{l}\text { A1 }-13 \text { anos } \\
\text { A2 }-5 \text { anos }\end{array}$ & $\begin{array}{l}\text { A1 - Apaixonou-se pela área / Identificação } \\
\text { A2 - Curiosidade }\end{array}$ \\
\hline Psicólogo & & P1 23 anos & P1 - Sempre gostou / Gostar \\
\hline Fisioterapeuta & & F1 2 anos & $\begin{array}{l}\text { F1 - Sempre gostou / Facilidade em lidar com } \\
\text { a criança }\end{array}$ \\
\hline
\end{tabular}

Fonte: Entrevistas dos sujeitos do estudo.

Eu fiz um ano de estágio, mais quatro meses agora como enfermeira. Então um ano e quatro meses (Alecrim).

Olha, eu não tenho muita experiência com as crianças portadoras de leucemia, até mesmo porque eu estou afastada do setor da oncologia [...] então assim eu quase não tenho muita experiência para falar de cuidados paliativos com crianças portadoras de leucemia (Beladona).

A falta de experiência na área faz com que os profissionais se posicionem à margem do projeto terapêutico e dos objetivos da abordagem paliativa da relação entre doente, família e equipe de saúde ${ }^{14}$.

Para que o cuidado paliativo se desenvolva de forma segura e satisfatória para os integrantes do processo, é necessário que todos tenham as mesmas atitudes voltadas para o bom desenvolvimento do trabalho, independente da experiência ou do tempo de atuação.

Toda a equipe deve ter condições de promover a assistência íntegra a indivíduos e suas famílias, sempre respeitando suas crenças e opiniões. A qualificação é muito importante para uma as- sistência prestada, o conhecimento ajuda na conduta perante um caso e compartilhar vivências também é muito importante para estender esse conhecimento nos cuidados à criança ${ }^{1}$. Para isso, é necessário que:

A equipe toda fale a mesma lingua senão não tem jeito, um fala uma coisa outro fala outra, gera aquele desconforto para a família. Não pensar só na criança pensar também no familiar que está adoecido com toda situação e isso é difícil falar porque a gente acaba ficando um pouco mecânica, infelizmente. No dia a dia a gente vai sendo tomada pelas coisas que vão acontecendo, mas acho importante, até para a gente lembrar de voltar um pouquinho atrás e dar uma freada e pensar no outro que está ali (Gérbera).

O profissional pensa na abordagem que deve ter com os familiares e tem a consciência de que o cuidado paliativo ainda é um enfrentamento difícil no cotidiano e nas inter-relações com a equipe e a família, o que pode dificultar ações coordenadas e em equipe ${ }^{15}$.

O profissional de saúde deve estar preparado para se deparar com situações de mudança nos 
aspectos biológicos e emocionais, pois a criança e sua família estarão fragilizados, como se constata no depoimento:

Essa fragilidade... geralmente o lado psicológico está muito afetado. Ela [a leucemia] vem com essa questão do risco físico mesmo, de mudanças. De medicação, de engorda, de perda de peso, às vezes, de perda de cabelo. Então isso influencia essa questão psicológica mesmo da criança, nessa parte a leucemia é muito difícil. Aí vai depender do acompanhante, dos pais, né? De responsáveis que possam atender, uns reagem de uma forma outros de outra, mas, na maioria das vezes, o que eu tenho notado muito é que é muito difícil! (Crisântemo Branco)

Para o profissional de saúde, vivenciar a história do paciente com câncer, inicialmente, pode ser algo incompreensível, que lhe causa angústia diante dos acontecimentos com o portador e com a família. Há sentimentos com que a equipe encontra dificuldades, como por exemplo, ser cuidador da criança e não se emocionar diante do sofrimento dela e de seus parentes; também é angustiante o sentimento da impossibilidade do agir, da sensação de que não é possível fazer mais nada pela pessoa, somente assistir ${ }^{6,16}$.

A realização do cuidado acontece seguindo os aspectos físico, emocional, social e espiritual; ignorando qualquer um desses aspectos o profissional torna a abordagem do paciente incompleta $^{17}$.

O contexto da atenção pediátrica pode trazer para o profissional a insegurança, o medo e dificuldades de enfrentamento para cuidar da criança em adoecimento, como relata o informante:

A minha parte de pediatria na faculdade foi muito sofrida, todos os meus professores me fizeram enfrentar esse medo. Porque não queria, não gostava de trabalhar em pediatria, gostava de criança sem estar no hospital (Pausa). Então eu formei e falei que um lugar que eu não queria trabalhar era na pediatria, não queria de forma alguma. Mas vim trabalhar aqui, fiquei um mês como plantonista noturna e me ofereceram a pediatria [...] primeiro eu não queria (pausa), pensei até em sair. Mas assim, em uma semana acabou, acabou... (risos) apaixonei e, assim... eu gosto de trabalhar com criança (Gérbera).

Como podemos analisar no Quadro 1, dos 17 entrevistados, 14 se identificam ou gostam de trabalhar na área pediátrica, somente dois manifestaram que sempre trabalharam na área $\mathrm{e}$ um manifestou que foi o setor onde melhor se adaptou.

Outra vertente é apresentada em relação à formação e à experiência em cuidados paliativos:
O profissional que atua nessa área, ele não pode ser um profissional que formou e não tem aquele embasamento de certo, né? De cuidado, de atenção com medicação de não errar, não é isso, nem é isso. Às vezes uma experiência, igual eu que tenho esta experiência, o meu cuidado maior quando eu estou na oncologia. Preparo-me psicologicamente, eu tenho que cuidar mais de mim quanto a isso [trabalhar na oncologia] você se envolve mesmo e você não pode deixar a peteca cair (Crisântemo Branco).

O enfrentamento no cotidiano de trabalho em oncologia requer, do profissional, um cuidado consigo mesmo e, segundo o informante, a experiência o auxilia no processo.

Os profissionais de saúde não são preparados durante a graduação para as situações de morte. Durante um processo de perda, esses profissionais vivenciam sentimentos de temor, insegurança e desamparo, pois, como a formação foi deficiente, eles não se sentem preparados para o enfrentamento da morte ${ }^{18}$.

Diante do que foi explanado, a abordagem paliativa requer uma boa estrutura psicológica da equipe multiprofissional, pois os profissionais são o apoio para a família. Com isso, percebe-se que, para a realização do trabalho, o profissional necessita gostar dessa área de atuação e fazer o que pode, além de entender todo o processo de (não)aceitação, revolta e estar preparado para cuidar paliativamente.

Então a gente tem que fazer por onde, eu penso assim, fazer o melhor pra esses meninos porque eles merecem, porque eles não têm culpa, sabe? Muitas vezes tem a fase da revolta fase de querer bater, de agredir, de xingar, a gente tem que estar preparada pra entender isso, ao mesmo tempo saber que aquilo ali vai passar, a revolta é passageira (Dormideira).

É de extrema importância que o profissional da saúde execute suas funções compartilhando informações e sentimentos para que o tratamento possa ser menos doloroso para a criança e familiares.

Para aqueles que cuidam de criança em processo de cuidado paliativo, é necessário haver simpatia, empatia, amor, compaixão e condições necessárias para o exercício da função de cuidador ${ }^{19}$.

A enfermagem, a profissão do cuidar, da assistência, ela é a que mais pode dar amor e mais cuidado pra essa criança. Claro que todas as disciplinas são importantes, o psicólogo, os médicos, são todos de extrema importância, mas quem tá na ponta, quem tá com contato direto com essa criança ali no dia a dia, é enfermagem né? Fora seus pais e tudo. Mas a enfermagem, o gostar do que faz, o 
amor à profissão, o amar aquela criança é extremamente importante pra você conseguir fazer um bom trabalho, você dar conforto nesse momento é difícil (Alecrim).

O trabalho em equipe favorece o desenvolvimento do tratamento, proporcionando ao paciente uma assistência de qualidade e de forma integral, o que pode facilitar a resposta ao tratamento.

A identificação com a área de atuação pediátrica proporciona aos profissionais um cuidado realizado com carinho e sentimento. A assistência integral das necessidades físicas, emocionais, sociais e espirituais da criança e de sua família, interfere na melhora da qualidade de vida do paciente e também na sensação de realização de um bom trabalho da equipe multiprofissional. O cuidado humano é uma experiência que engrandece a pessoa não apenas como profissional, mas como ser humano ${ }^{20}$.

Eu acabei me apaixonando, adoro trabalhar no setor de pediatria (Alfazema).

Eu gosto do que eu faço, gosto de ajudar o próximo (Crisântemo Branco).

O profissional da saúde que atua na área que tem afinidade e lhe apraz detém de uma habilidade para apoiar e persistir para o andamento satisfatório do tratamento, com ações fundadas em zelo e na comunicação efetiva com a criança e seus familiares, proporcionando um cuidado integral ao paciente respeitando-o como pessoa.

No Quadro 1, pode- se verificar que o profissional, na maioria das vezes, se encontra na área pediátrica por identificação e amor pela criança. O que contribui para o cuidado, pois podem realizar suas funções com segurança, conforto e afeto, consequentemente os pais, os familiares e as crianças em adoecimento desenvolvem a confiança no profissional, tendo-o como referência.

O relacionamento humano é a base do cuidado que sustenta a fé e a esperança do portador de doença que já se apresenta em estágio avançado ou período terminal. A compaixão e o afeto com a pessoa trazem a certeza de que fazemos parte de um conjunto que nos traz realização, alegria e paz ${ }^{21}$.

É, são crianças que, na verdade, precisam de toda atenção, carinho da gente. Temos algumas crianças que são meio depressivas, ficam carentes, sentem muita dor, então assim o papel da gente além de cuidar da criança, é não deixar a criança sentir dor em tempo nenhum, porque acho que não tem coisa pior do que sentir dor. Então acho, que requer toda essa atenção por parte psicológica, da parte de cuidado de enfermagem, dar atenção o tempo todo, eu penso assim (Girassol).

Olha, a partir do momento em que você trata todos por igual [independente da doença], você tem condições de dar para aquela criança com leucemia uma nova esperança, entendeu? Pra ela não ficar se achando uma coitada, porque ela não é uma coitada no meio de nós. Ela é uma pessoa que está com um problema de saúde que infelizmente é um pouco mais sério que os outros (Beladona).

O vínculo com a área é analisado pela compreensão do cuidado, sendo que o cuidar está além do biológico e a criação de valores que estabelece esse vínculo acontece pela reflexão contínua entre profissional/paciente/família. A equipe consegue não só criar valores morais como tomar condutas éticas, proporcionando uma reflexão sobre limites e possibilidades ${ }^{22}$.

Assim, cuidar da criança em fase terminal remete à humanização e à criação de vínculo para que as experiências vividas sejam significantes e afetuosas para profissionais e seres cuidados.

\section{Considerações finais}

O cuidado paliativo em crianças portadoras de leucemia é uma área de atuação que requer equilíbrio psicológico da equipe, pois a mesma serve como ponto de apoio para o paciente e para sua família. Observou-se que o profissional acolhe e presta assistência humanizada à criança portadora de leucemia em cuidado paliativo, proporcionando-lhe o máximo de conforto e diminuição da dor. Constatou-se que a abordagem paliativa multiprofissional realizada engloba não somente o portador de leucemia, mas também alcança a sua família.

Verificou-se que os profissionais possuem pouca experiência na realização do cuidado paliativo e têm dificuldade em lidar com os sentimentos, sentindo-se, às vezes, impossibilitados de agir mediante as angústias dos envolvidos e com a morte. Percebeu-se que o experimento cotidiano em cuidado paliativo os fortalece, mas é necessário aprofundamento sobre esse tema.

Contudo, apesar de a área de atuação gerar muito sofrimento e angústia ao profissional, percebe-se que a equipe multiprofissional identificase e gosta da área de atuação o que é importante para a criança e sua família se sentirem seguros, respeitados e acolhidos pelos profissionais. 


\section{Colaboradores}

DM Nascimento, TG Rodrigues, MR Soares e MLS Rosa trabalharam na concepção, na pesquisa, na análise, na interpretação dos dados, na redação final. SMF Viegas trabalhou na concepção, na pesquisa, na análise, na interpretação dos dados, na redação final, na revisão crítica. PO Salgado trabalhou na revisão crítica.

\section{Referências}

1. Kruse MHL. Cuidados paliativos: uma experiência. Rev HCPA 2007; 27(2):69-73.

2. Miller M, McKinney PA, Parslow RC, Feltbower RG. Referral to a specialist paediatric palliative care service in oncology patients. Pediatr Blood Cancer 2011; 56(4):677-680.

3. Organização Mundial de Saúde (OMS). Medicina paliativa: cuidados e medicamentos. 2007. [acessado 2012 mai 5]. Disponível em: http://www.who. int/cancer/palliative/en/

4. Souza KC, Carpigiane B. Ditos, não ditos e entreditos: a comunicação em cuidados paliativos. Psicologia: Teoria e Prática 2010; 12(1):97-108.

5. Costa TF, Ceolim MF. A enfermagem nos cuidados paliativos à criança e adolescente com câncer: revisão integrativa da literatura. Revista Gaúcha de Enfer, 2010. 31(4):776-784.

6. Sales CA, Silva MRB, Borgognoni K, Rorato C, Oliveira WT. Cuidado paliativo: a arte de estar-como-outro de uma forma autêntica. Rev. enferm. UERJ. 2008, 16(2):174-179.

7. Matos E, Pires DEP. Práticas de cuidado na perspectiva interdisciplinar: um caminho promissor. Texto Contexto Enferm. 2009; 18(2):338-346.

8. Bifulco VA, Iochida LC. A formação na graduação dos profissionais de saúde e a educação para o cuidado de pacientes fora de recursos terapêuticos de cura. Rev. bras. educ. med. 2009; 33(1):242-248

9. Minayo MCS. Análise qualitativa: teoria, passos e fidedignidade. Cien Saude Colet 2012; 17(3):621-626.

10. Bardin L. Análise de conteúdo. Lisboa: Edições 70; 2011.

11. Minayo MCS. O desafio do conhecimento: pesquisa qualitativa em saúde. 10a Edição. São Paulo: Hucitec; 2007.

12. Yin RK. Estudo de caso: planejamento e métodos. Porto Alegre: Bookman; 2005.

13. Viegas SMF. A integralidade no cotidiano da Estratégia Saúde da Família em municípios do Vale do Jequitinhonha-Minas Gerais [tese]. Belo Horizonte: Universidade Federal de Minas Gerais; 2010.

14. Brasil. Ministério da Saúde. Conselho Nacional de Saúde. Resolução nº 196 de 10 de outubro de 1996. Diretrizes e Normas Regulamentadoras de Pesquisas Envolvendo Seres Humanos. Diário Oficial da União 1996; 16 out.

15. Oliveira AC, Silva MJP. Autonomia em cuidados paliativos: conceitos e percepções de uma equipe de saúde. Acta Paul Enferm. 2010; 23(2):212-217.

16. Silva AE. Cuidados Paliativos de Enfermagem: perspectivas para equipe de enfermagem [tese]. Divinópolis: Universidade do Estado de Minas Gerais, Fundação Educacional de Divinópolis; 2008.

17. Peres $M F P$. A importância da integração da espiritualidade e da religiosidade no manejo da dor e dos cuidados paliativos. Psiq. Clín. 2007; 34(Supl. 1):82-87.

18. Santos JS, Bueno SMV. Educação para a morte a docentes e discentes de enfermagem: revisão documental da literatura científica. Rev. esc. enferm. 2009; 45(1):272-276. 
19. Araújo LZS, Araújo CZS, Souto KBA, Oliveira MS. Cuidador principal de paciente oncológico fora de possibilidade de cura, repercussões deste encargo. Rev. Bras.de Enferm. 2009; 62(1):32-37.

20. Brasil. Academia Nacional de Cuidados Paliativos. Manual Nacional de Cuidados Paliativos. Rio de Janeiro, 2009. [página na Internet]. [acessado 2012 mai 6]. Disponível em: http://www.nhu.ufms.br/ Bioetica/Textos/Morte\%20e\%20o\%20Morrer/ MANUAL\%20DE\%20CUIDADOS\%20PALIATIVOS.pdf

21. Araújo MMT, Silva MJP. A comunicação com o paciente em cuidados paliativos: valorizando a alegria e o otimismo. Rev. Esc. enferm. 2007; 41(4):668674.

22. Silva MM, Moreira MC. Sistematização da assistência de enfermagem em cuidados paliativos na oncologia: visão dos enfermeiros. Acta Paul. Enferm 2011; 24(2):72-78.

Artigo apresentado em 30/04/2013

Aprovado em 22/05/2013

Versão final apresentada em 09/06/2013

\section{ERRATA}

Ciência \& Saúde Coletiva

volume 18 número 9 - 2013

\section{p. 2721}

\section{onde se lê:}

${ }^{2}$ Universidade Federal de Viçosa.

${ }^{3}$ Escola de Enfermagem, Universidade Federal de Minas Gerais.

\section{leia-se:}

${ }^{2}$ Universidade Federal de São João del-Rei.

${ }^{3}$ Universidade Federal de Viçosa. 